\title{
New Brand Names and Inferential Beliefs: Some Insights on Naming New Products
}

\author{
George M. Zinkhan
}

University of Houston

\author{
Claude R. Martin, Jr. \\ University of Michigan
}

\begin{abstract}
Consumers' attitudes toward names were studied and evidence was found that attitude toward a brand name exists independently of attitude toward a product or brand. A method for measuring attitudes toward names is demonstrated. In a multiple regression setting, four predictor variables-number of purchases, product interest, cognitive differentiation, and product experience-were found to explain up to $34 \%$ of the variance associated with brand name attitudes.
\end{abstract}

Introduction

A brand name is something more than a label; a brand name may be a major product attribute and a part of what the consumer buys [6]. It is a complex symbol that has the potential to represent many ideas and attributes associated with the product it represents [20]. As such, it may be possible for consumers to form complex attitudes toward the brand name. These attitudes can be based on the literal meaning of the name, the way the name sounds, or some associations that the brand name accumulates over time due to company promotion or individual usage [20]. Brand name conveys information to the consumer; for example, RigauxBricmont [27] has found that brand name can influence consumers' quality evaluations of a product. Beyond this, it seems that a brand name can have a certain "meaning" to people - this meaning being independent of any particular promotion or usage experience. Advertisers appreciate this fact and devote considerable time and effort to selecting just the right name. Prior rescarch suggests that consumers are more likely to associate a certain word or sound with certain product categories than with others [26]. The advantages of a familiar brand name are also revealed by Bogart and Lehman's [4] research, based upon free recall of brand names, showing "that a new product has a better chance for acceptance if it comes in under an old brand name."

Promoting a new or unfamiliar product can be considered a type of paired associate learning, where the consumer is to learn to associate a particular brand or company name with a product or service [21]. Some candidate brand names arc

Send correspondence to George M. Zinkhan, Department of Marketing, University of Houston, University Park, Houston, Texas 77004. 
Step 1. Exposure to a brand name:

Step 2. Image of the new brand name is formed

Step 3. Inferential beliefs are formed:

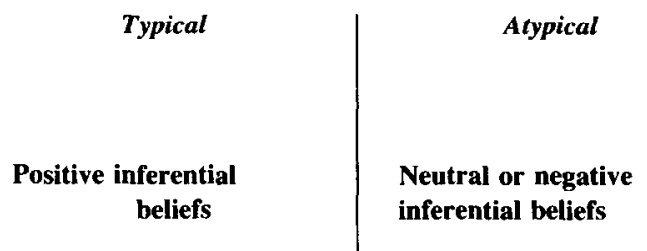

inferential beliefs

Figure 1. The Formation of Attitudes Towards New Brand Names

more memorable than others in the sense that they seem to belong to a particular product category. Here, we call these memorable names "typical names" and define a typical brand name as one which calls to mind imagery that reminds the consumer of the product category.

Sometimes there may be a close connection between meaningfulness and imagery. Generic brand or company names, such as Stork Diaper Service and Minuteman Timeclock Corporation, are typical and memorable because of the imagery they conjure up [21]. Other times, however, imagery-producing mechanisms are much more subtle. For example, Peterson and Ross [26] found that some randomly generated syllables are more "remindful" of a particular product class than are other randomly generated syllables. "Remindfulness" can result from many factors including onomatopoeia, plural sounds, and "typicality". The purpose of this paper is to examine the strength of brand name imagery and to identify some of the individual difference variables that might explain the differing effects of brand name imagery. We demonstrate a method of measuring consumers' attitudes toward names $\left(\mathrm{Att}_{\mathrm{Name}}\right)$ and explore the different effects of various new brand names.

\section{The Process of Att Name $_{\text {Formation }}$}

As shown in Figure 1, consumers form attitudes about brand names through a four stage process. At the first step, consumers are exposed to a new brand name for the first time; this new name can be either typical (similar or remindful of other names in the product category) or atypical (dissimilar to other names in the category). This exposure, when perceived, leads to the formation of a brand image. Gardner and Levy [14] describe this as a "public image, a character or personality that may be more important for the overall status (and sales) of the brand than many technical facts about the product." Lutz and Lutz [21] have demonstrated the effect that this brand image can have on consumer information processing.

At the third step, inferential beliefs can be formed about the new brand. As shown in Figure 1, perception of a typical brand name is expected to lead to the formation of positive inferential beliefs. Perception of an atypical brand name leads to neutral or negative beliefs. These beliefs are not directly related to environmental cues but, instead, are inferred from them. Since brand name is the only cue present, these inferential beliefs are a result of brand name. The overall attitude that represents a composite of those beliefs is defined as brand name attitude $\left(\mathrm{Att}_{\mathrm{Namc}}\right)$, as shown in the final stage of Figure 1. Following Zinkhan and Martin [33], Att Name $_{\text {e }}$ can be described as the composite of knowledge, beliefs, and feelings that a person has and takes into account when responding to an object. In this investigation we 
want to determine the effect of brand name imagery on the belief structure associated with a new brand. Thus, we are interested in studying the formation of attitude rather than attitude change.

\section{Inferential Belief Formation}

One purpose of promotion is to change consumers' beliefs about brands. Sometimes, however, people seem to make inferences about brand characteristics even when no relevant information is provided in a promotional message [23]. In other words, by some inferential process, people may develop beliefs about brand attributes based on minimal brand specific information. If information is provided about brand name and there is no other source of information, then consumers may develop beliefs concerning other characteristics the newly named brands must have. Potentially, there are many other sources of inferential beliefs about a brand besides the brand name. For example, if a friend tells a consumer that a new brand of ice cream "tastes good," then that consumer may infer that the new ice cream also has a creamy texture. In other words, consumers may infer beliefs based on word of mouth or may infer beliefs from related attribute values.

This process of inferential belief formation can be explained by the pattern of prior semantic association in memory [23]. That is, people have structures of knowledge that may be used as a basis for interpreting new information and for making inferences [24, 25]. For instance, if consumers believe that a new camera has a name that is pleasing or satisfying, then they may make the inference that this camera can do all the things that other cameras do-such as take good pictures $[32,33]$. In this way new beliefs may be formed based on only one piece of information (e.g., brand name). Memory structures for generic product categories may provide default values that enable a person to make assumptions about specific attributes when information is missing [23]. Faced with a paucity of information, individuals may assume average values in the place of missing information. For example, if a camera's size is not known, then the camera may be assumed to be of some standard or typical size.

In this way, consumers may form conclusions about a new brand when the only available cue in the environment is brand name itself. A distinction is made here between descriptive beliefs (which are directly related to environmental cues) and inferential beliefs (which are inferred from environmental cues). Both types of beliefs-descriptive and inferential-can influence the global evaluation of a concept, according to expectancy-value theory $[12,24]$. Here we are interested in exploring the effect brand name can have on this inferential process. How strong are the inferential beliefs that consumers form as a reaction to the brand name cue?

Huber and McCann [17], while investigating the effect of inferential beliefs on product evaluations, found that the "the impact of inferential beliefs can occur and can be very significant." These authors go on to suggest that "what is needed to understand this phenomenon is a theory and empirical work detailing the contexts in which these inferences occur" (p. 332). Such an attempt is made here. Inferential belief formation is studied in a situation where consumers have information only about brand name. However, it must be emphasized that this situation is artificial in that it is rare for brand name to be the only cue available to consumers. 


\section{Conceptual Framework and Hypotheses}

The objectives of this study are three-fold:

1. to investigate the attitudes consumers form, based on exposure to brand name alone;

2. to investigate the effects that typical and atypical brand names have on Att $_{\text {Name }}$;

3. to investigate individual characteristics that may affect the formation of brand attitudes.

When will positive attitudes toward a brand name be produced? For best results, Elling [10] suggests that a new brand name should have approximately the same semantic characteristics as competing products since the customers may have preconceived ideas or opinions about the semantic characteristics of a product name. As mentioned above, a typical name may be best for any given product category, with a typical name being defined as a name which evokes imagery that reminds the consumer of the product category. Peterson and Ross [26] find empirical evidence to support this point of view, and they suggest that it is good marketing strategy to choose brand names that possess some congruence with names of existing or competing brands. This suggests the first hypothesis:

$\mathrm{H}_{1}$ : Exposure to a new, typical brand name will result in a more favorable attitude formation than exposure to a new, atypical brand name.

\section{Predictors of Att Name $_{\text {na }}$}

Beyond the characteristics of the name itself, individual characteristics may be important for predicting the formation of favorable attitudes toward the brand's name. Two potential predictors of $\mathrm{Att}_{\mathrm{Name}}$ are derived from corollaries of the Howard-Sheth model. The original Howard-Sheth model hypothesized that customers move between the stages of extensive problem solving, limited problem solving, and routine response behavior based upon the number of trials within a particular product category [16]. The more purchases a person makes, the stronger are his attitudes toward brands in that category. Since the majority of purchases result in a satisfactory experience [13], these strong attitudes toward familiar brands within a product category tend to be favorable in nature. These favorable associations build up as a consumer makes purchases and acquires experience with the brands in a given product category. These associations can be transferred to a new entrant in the category through a process of belief inference.

$\mathrm{H}_{2}$ : Consumers with high experience levels within a product category will be likely to have favorable attitudes toward a new, typical brand name.

$\mathrm{H}_{3}$ : A large number of prior purchases within a product category will be associated with favorable attitudes toward a new, typical brand name.

Those with strongly formed attitudes toward brands within a generic product class should then be likely to infer beliefs about properties of a new, typically named brand. For instance, a person who has a lot of experience with cameras would consider it likely that the typically named brand will sell for a usual price.

Bagozzi [2] states this notion in a slightly different fashion: "Because the ex- 
pectancy-value measures [of attitude] elicit relatively specific cognitive and evaluative reactions, it is expected that crystalized attitudinal responses will occur for those with prior experience with the attitudinal act." When a consumer has a lot of experience or familiarity with a particular product class, she is likely to form positive attitudes about brands within that class, and through a process of inferential belief formation, she will transfer these positive attitudes to new, typically-named brands.

The final two hypotheses relating to $\mathrm{Att}_{\mathrm{Name}}$ are derived from semantic memory theory $[24,25]$. According to this theory, experience within a product category can lead to the formation of memory schemata. And these schemata may be activated and used as a basis for interpreting new information and for making inferences [23]. Those with highly developed schemata are more likely to make inferences than those with less-developed schemata. Durand [9] presents empirical evidence to suggest that complex cognitive structures are associated with the existence of well-developed attitudinal structures and, therefore, are associated with the formation of favorable inferential beliefs.

It has been proposed that memory schemata are the basic memory structures enabling consumers to make attributions [23]. Complex cognitive structures are expected to be closely associated with the formation of inferential beliefs. The schemata concept, then, can be seen as a theoretical representation of the cognitive structure created by past experiences [23]. Those who have an established knowledge structure for a particular product category are expected to utilize this structure to draw conclusions about product characteristics when the only cue available in the environment is brand name.

$\mathrm{H}_{4}$ : Consumers with complex cognitive structures will be likely to have favorable attitudes toward new, typical brand names.

It is certainly possible that those with established knowledge structures will make negative, as well as positive, inferences about a new brand. However, since North American consumers are generally satisfied with the products they use [1], we can expect more positive inferences than negative.

A person who is especially interested in a product class would be expected to have strong attitudes about the brands in that category. Sometimes these strong attitudes are negative, but they are probably positive more often than negative. This is shown in studies by Diener and Greyser [7] and Westbrook et al. [31], who conclude that American consumers have overwhelmingly positive experiences with the products they purchase and use. Again, these favorable associations are expected to transfer to the typically named brands through the mechanism of belief inference. Thus, the final hypothesis:

$\mathrm{H}_{5}$ : Consumers with high interest levels in a product category will be likely to form a favorable attitude toward a new, typical brand name.

\section{Method}

\section{Stimuli}

Two product categories were investigated-cameras and ice cream. Within these product categories, four brand names were developed-two typical of the category 
Table 1. Typical and Atypical Brand Namcs-Pretest Results

\begin{tabular}{lcccc}
\hline & \multicolumn{1}{c}{$\begin{array}{c}\text { Brand } \\
\text { Names }\end{array}$} & $\begin{array}{c}\text { Mean } \\
(\bar{X})\end{array}$ & $\begin{array}{c}\text { Standard } \\
\text { Deviation }\end{array}$ & $t$-statistic \\
\hline Atypical & 1. Pilot & 2.3 & 1.9 & - \\
Camera Brands: & 2. Wylens & 1.4 & 1.1 & - \\
Typical & 3. Mishu & 6.4 & 1.6 & - \\
Camera Brands: & 4. Solar $X$ & 6.1 & 1.7 & - \\
& Difference $\left(\bar{X}_{3}-\bar{X}_{1}\right)$ & 4.1 & - & $14.39^{a}$ \\
& Difference $\left(\bar{X}_{3}-\bar{X}_{2}\right)$ & 5.0 & - & $22.42^{a}$ \\
& Difference $\left(\bar{X}_{4}-\bar{X}_{1}\right)$ & 3.8 & - & $13.01^{a}$ \\
Atypical & Difference $\left(\bar{X}_{4}-\bar{X}_{2}\right)$ & 4.7 & - & $20.26^{a}$ \\
Ice Cream Brands: & 5. Pharaoh & 1.8 & 1.3 & - \\
Typical & 6. El Orbii & 1.3 & 0.9 & - \\
Ice Cream Brands: & 7. Polar Bear & 6.7 & 2.3 & - \\
& 8. Lorentzens & 5.8 & 1.4 & - \\
& Difference $\left(\bar{X}_{7}-\bar{X}_{5}\right)$ & 4.9 & - & $16.17^{a}$ \\
& Difference $\left(\bar{X}_{7}-\bar{X}_{6}\right)$ & 5.4 & - & $19.08^{a}$ \\
& Difference $\left(\bar{X}_{8}-\bar{X}_{5}\right)$ & 4.0 & - & $18.26^{a}$ \\
& Difference $\left(\bar{X}_{8}-\bar{X}_{6}\right)$ & 4.5 & - & $23.56^{a}$ \\
\hline
\end{tabular}

${ }^{a} p<0.001$ (using the Bonferroni method of simultaneous inference [22]).

and two atypical. Table 1 presents the typical and atypical brand names selected. Fictitious brands were used to eliminate prior attitudinal effects. Previous researchers have used nonsense syllables $[20,26]$ or letters of the alphabet [23] in the place of brand names to minimize brand imagery. In this investigation, we were interested in creating a more realistic situation by using names that could be actual candidates for a new brand.

Two methods were employed to insure that the selected names were in fact typical (or atypical). First, 76 subjects were presented with a group of fictitious brand names and instructed to indicate how much each brand reminded them of the product category. Each candidate brand name was rated on a seven-point scale ranging from "Doesn't remind me at all" to "Reminds me very much" [see 26]. The selected names and pretest results are shown in Table 1. The $t$ tests for differences between means show that the typical names are more remindful of the respective product categories than the atypical names.

As a second manipulation check, a group of four experts-all of whom worked for advertising agencies - rated a group of fictitious brand names. The results of these expert ratings concur with the classification of typical and atypical brand names represented in Table 1.

\section{Experimental Procedure}

The subjects in the main experiment met for two sessions. In the first session, they indicated their interest, experience, number of purchases, and cognitive differentiation for a group of product categories. In the second session, Att $_{\text {Name }}$ was assessed for the two product categories. In both sessions, presentation of categories was rotated.

The first hypothesis was evaluated using a $t$ test to determine if belief components were different for typical versus atypical brand names. Hypotheses 2 through 5 
Table 2. Mcasurcment of Product Interest and Experience

Product Interest Items

1. Involvement: "I can make many conncctions or associations between events in my life and this product" (seven-pont Likert-type scale).

2. Buchanan's [5] measure of relative interest: Subjects are shown the names of nine products arranged in twelve groups of three each, and asked to indicate which of the three categories they would most like to read a message about and which they would least prefer to read a message about. The output from this procedure provides a relative measure of involvement.

Estimate of coefficient alpha $\quad \longrightarrow .79$

Experience Items

Expertise: "How expert do you consider yourself with respect to cameras?" (seven-point scale with endpoints of "not very expert" and "very expert").

Experience: "How experienced are you with cameras?" (seven-point scale with endpoints of "not at all experienced" and "very experienced").

Estimate of coefficient alpha $\quad-0.84$

were tested by multiple regression analysis. Att $_{\mathrm{Name}}$ served as the criterion variable, and product interest, number of purchases, cognitive differentiation and experience were the predictor variables. For each product category investigated, one sample was used to estimate the model, and predictions are made to a hold-out sample to validate the model.

\section{Subjects}

Two groups of subjects were used in the main experiment. The first group consisted of 108 students at a major Midwestern University. The validation sample consisted of 82 adults, selected from a Southwestern metropolitan area. Goodwin and Etgar [15] have suggested that student subjects may be entirely acceptable and consistent with improved external validity if the product classes selected for study are particularly salient to them. This notion was tested empirically by employing a validation sample of nonstudents. In this way, it could be determined if the model estimated with student subjects was generalizable to a wider population.

\section{Measurement}

\section{Measurement of Predictor Variables}

Product interest and experience were calculated using multiple measures. The items and estimates of coefficient alpha are presented in Table 2. Number of camera purchases was measured by asking respondents to indicate how many times they have purchased a camera in the last seven years. Number of ice cream purchases was measured in a similar manner but using a shorter period (average number of purchases per month). Both variables were then coded in identical time units (purchases per year).

Cognitive differentiation occured in two stages [30]. First, in a free format, 
respondents listed all the important attributes they could think of as associated with cameras. Second, respondents put these attributes into groups based on their similarities. A respondent could make as many or as few groups as seemed appropriate. A measure of cognitive differentiation was calculated according to a formula derived from information theory [33]:

$$
H=\sum_{i=1}^{n} p_{i} \log _{2}\left(1 / p_{i}\right)=\log _{2}(n)-1 / n \sum_{i=1}^{n} n_{i} \log _{2}\left(n_{i}\right),
$$

where $n$ is the total number of attributes, $n_{i}$ is the number that appears in a particular combination of groups, and $p_{i}=n_{i} / n$.

$H$ may be treated as an approximate measure of the dimensional complexity of the cognitive domain referring to a particular class of attributes. It is a purely structural property, because it does not depend on the content of the attributes but on the relations (similarity or dissimilarity) among them [30].

An additional measure $R$, or the index of relative entropy, may be used to correct for varying numbers of attributes initially listed by different subjects:

$$
R=H / \log _{2}(n) \text {, }
$$

where $n$ is the number of attributes listed by the subject. Whereas $H$ represents the absolute complexity of the subject's category system, $R$ may be interpreted as the complexity relative to the number of attributes to be comprehended. $R$ thus tends to correct downwards the cognitive differentiation scores of subjects who name a large number of product attributes without fully distinguishing among them [30]. Consequently, we used a subject's $R$ score as a measure of cognitive differentiation in this investigation. Notice that originally the formulation of this concept- $R$-required subjects to list and group objects rather than to list and group attributes. In other words, a high $R$ score indicates that a subject is able to observe objects within a domain as distinct from one another. Under the procedure employed in this study, subjects placed attributes into groups, and thus a high $R$ score indicates that a subject observed product attributes as distinct from one another. The $R$ measure, used here as a notion of cognitive differentiation, is consistent with that of Bieri et al. [3].

\section{Measurement of $A t_{\text {Name }}$}

Att $_{\text {Name }}$ was measured in two stages. First, subjects indicated how important five product attributes were using a 7-point scale. During the second stage, subjects were told that a new brand was being introduced and that distributors were interested in their reactions to the brand name. For each stimulus, subjects were presented with a piece of paper that contained a product category (e.g., ice cream) and the brand name of interest (e.g., Polar Bear). After thinking about these brand names for one minute, subjects indicated their beliefs about the new brand, using a seven-point scale.

Essentially, attitude toward the brand name was measured using Fishbein's [12] attitude model:

$$
A_{o}=\sum_{i=1}^{n} B_{i} a_{i}
$$


where $A_{o}$ represents an individual's attitude toward (overall evaluation of) a particular brand $(o) ; B_{i}$ is the strength of the association between the attitude concept, $o$, and the $i$ th salient concept; $a_{i}$ represents the evaluation of concept $i$; and $n$ is the number of salient concepts. Reviewing the attitude measurement equation above, note that marketing researchers have been mainly concerned with consumers' beliefs about attributes of a brand [23]. The beliefs associated with using the brands are measured on a seven-point scale. Ryan and Bonfield [29] have demonstrated that scales following Fishbein's belief statement typology should be bipolar and should be scored from -3 to +3 . This logic is followed here and the belief scale is coded with +3 as the most positive rating, -3 as the most negative rating, and 0 as the midpoint.

It is important that the component beliefs in the expectancy value model reflect the factors salient in the formation of attitudes. Consequently, pretests employing free elicitation procedures were conducted to isolate the important attributes associated with cameras and ice cream. For cameras, the most salient attributes proved to be: price, ease of focus, interchangeability of lenses, bulkiness, and ease of film insertion. For ice cream the salient attributes were price, ingredients, taste, packaging, and texture. Therefore, five attributes are used to represent the product categories. This is in line with an accepted rule of thumb stating that "a person's attitude toward an object is primarily determined by no more than five to nine beliefs about the object" [12].

To test whether the measurement instruments might interact in an undesirable manner, a control group of subjects ( $N=55$, drawn from the same subject pool as those in the main experiment) also participated in two sessions. In the first session they performed an unrelated task; and in the second session they took the $\mathrm{Att}_{\text {Name }}$ questionnaire. Analysis-of-variance results reveal no difference in the attitude scores for either the camera $(F=1.45 ; \mathrm{df}=1,161)$ or the ice cream brands $(F$ $=0.84, \mathrm{df}=1,161)$. Thus, the process of measuring the predictor variables does not subsequently affect subjects' brand name attitudes.

Results

\section{Results for Hypothesis 1: Beliefs Associated with Typical and Atypical Brand Names}

To test the first hypothesis, average belief values were computed for both typical and atypical brand names. For example, Table 3 shows the average belief rating for the price of the two atypical camera brands as 0.864 . Likewise, the mean price rating associated with the two atypical camera brands (Pilot and Wylers) is 0.118 . Next, these mean price ratings (typical vs. atypical) are subtracted, and a $t$ statistic is used to test for a difference between means. This test is performed to determine if typicality matters.

In the case of the camera brands (shown in Table 3), all five differences are positive, indicating that the typical brands are more favorably rated than atypical brands. The $t$ tests reveal that four out of five of these differences are significant at the 0.001 level or below.

A similar pattern is found for the ice cream brands (see Table 3). Again, all five contrasts are positive, indicating that the typical brands are rated more posi- 
Table 3. Difference between Mcan Belief Ratings

\begin{tabular}{lccccc}
\hline \multicolumn{1}{c}{ Beliefs } & $\begin{array}{c}\text { Mean Rating for } \\
\text { Typical Brands } \\
(\bar{X} T)\end{array}$ & $\begin{array}{c}\text { Mean Rating for } \\
\text { Atypical Brands } \\
(\bar{X} A)\end{array}$ & $\begin{array}{c}\text { Differences } \\
\text { between means } \\
(\bar{X} T-\bar{X} A)\end{array}$ & $t$-statistic & $p<$ \\
\hline Camera price & 0.864 & 0.118 & 0.746 & 7.54 & 0.001 \\
Ease of focus & 0.816 & 0.020 & 0.796 & 8.11 & 0.001 \\
Lenses & 0.113 & -0.032 & 0.145 & 1.36 & 0.20 \\
Bulkiness & 1.337 & 0.224 & 1.113 & 11.24 & 0.001 \\
Film insertion & 0.725 & 0.127 & 0.598 & 6.29 & 0.001 \\
Ice cream price & 0.947 & -0.319 & 1.266 & 15.50 & 0.001 \\
Ingredients & 1.021 & 0.138 & 0.883 & 9.11 & 0.001 \\
Taste & 1.158 & 0.971 & 0.187 & 2.20 & 0.05 \\
Packaging & 1.376 & 0.641 & 0.735 & 7.53 & 0.001 \\
Texture & 1.469 & -0.423 & 1.892 & 23.36 & 0.001 \\
\hline
\end{tabular}

tively. Four of the five differences are significant at the 0.001 level and the remaining difference (for taste) is significant at the 0.05 level. Thus, fairly strong support is found for the first hypothesis. All contrasts are in the expected direction, with typical brands receiving higher ratings than atypical brands. Nine out of these ten contrasts are found to be significant beyond the 0.05 level, and generally, the typical brands are perceived in a more positive light than the atypical brands.

\section{Results for Hypotheses 2 through 5: Individual Difference Variables Associated with Typical Names}

Table 4 presents the observed relationships between the camera brand names and product interest, number of purchases, cognitive differentiation, and product experience. Beta weights, partial correlations, and correlation coefficients are cal-

Table 4. Multiple Regression Results-Camera Brands

\begin{tabular}{|c|c|c|c|c|}
\hline \multicolumn{2}{|c|}{$\begin{aligned} \text { Dependent Variable }= & \begin{array}{l}\text { First Camera } \\
\text { Brand Name }\end{array}\end{aligned}$} & \multicolumn{2}{|c|}{$R^{2}=.308$} & \multirow{2}{*}{$\begin{array}{l}N=98 \\
\text { Correlation }\end{array}$} \\
\hline & $\begin{array}{l}\text { Beta } \\
\text { Weight }\end{array}$ & $\begin{array}{l}\text { Standard Error } \\
\text { (Beta Weight) }\end{array}$ & $\begin{array}{c}\text { Partial } \\
\text { Correlation }\end{array}$ & \\
\hline Product experience & $0.266^{a}$ & 0.088 & 0.300 & 0.269 \\
\hline Number of purchases & $0.197^{b}$ & 0.088 & 0.226 & 0.245 \\
\hline Cognitive differentiation & $0.287^{a}$ & 0.087 & 0.325 & 0.282 \\
\hline Product interest & $0.331^{a}$ & 0.088 & 0.365 & 0.325 \\
\hline \multicolumn{2}{|c|}{$\begin{aligned} \text { Dependent Variable }= & \text { Second Camera } \\
& \text { Brand Name }\end{aligned}$} & \multicolumn{2}{|c|}{$R^{2}=.174$} & $N=101$ \\
\hline & $\begin{array}{c}\text { Beta } \\
\text { Weight }\end{array}$ & $\begin{array}{l}\text { Standard Error } \\
\text { (Beta Weight) }\end{array}$ & $\begin{array}{c}\text { Partial } \\
\text { Correlation }\end{array}$ & Correlation \\
\hline Product experience & 0.034 & 0.125 & 0.028 & 0.279 \\
\hline Number of purchases & $0.225^{b}$ & 0.103 & 0.218 & 0.300 \\
\hline Cognitive differentiation & $0.204^{b}$ & 0.096 & 0.213 & 0.222 \\
\hline Product interest & $0.197^{\mathrm{c}}$ & 0.115 & 0.173 & 0.260 \\
\hline
\end{tabular}

${ }^{a}$ Beta coefficient significant $p<0.01$ (all beta coefficients are standardized)

${ }^{b}$ Beta coefficient significant $p<0.05$

Beta coefficient significant $p<0.10$ 
Table 5. Multiple Regression Results-Ice Cream Brands

\begin{tabular}{lcccc}
\hline $\begin{array}{l}\text { Dependent Variable }=\begin{array}{c}\text { First Ice Cream } \\
\text { Brand Name }\end{array} \\
\text { Weta } \\
\text { Weight }\end{array}$ & $\begin{array}{c}\text { Standard Error } \\
\text { (Beta Weight) }\end{array}$ & $\begin{array}{c}\text { Partial } \\
\text { Correlation }\end{array}$ & Correlation \\
\hline Product experience & 0.018 & 0.094 & 0.019 & 0.240 \\
Number of purchases & $0.322^{a}$ & 0.094 & 0.328 & 0.460 \\
Cognitive differentiation & $0.166^{c}$ & 0.085 & 0.195 & 0.238 \\
Product interest & $0.282^{a}$ & 0.097 & 0.284 & 0.437 \\
\hline Dependent Variable $=$ Second Ice Cream & \multicolumn{2}{c}{$R^{2}=0.345$} \\
& Brand Name & & $N=102$ \\
\hline & Beta & Standard Error & Partial & \\
& Weight & (Beta Weight) & Correlation & Correlation \\
\hline Product experience & 0.119 & 0.093 & 0.129 & 0.350 \\
Number of purchases & $0.264^{a}$ & 0.101 & 0.257 & 0.475 \\
Cognitive differentiation & $0.187^{b}$ & 0.083 & 0.223 & 0.255 \\
Product interest & $0.276^{a}$ & 0.097 & 0.277 & 0.472 \\
\hline
\end{tabular}

${ }^{a}$ Beta Coefficient Significant $p<0.01$ (all beta coefficients are standardized)

${ }^{b}$ Beta Coefficient Significant $p<0.05$

'Beta Coefficient Significant $p<0.10$

culated. All coefficients are signed in the hypothesized direction. With respect to the first camera brand name, over $30 \%$ of the variance is accounted for by the four predictor variables, and beta weights associated with all four predictors are significant $(p<0.05)$. The results associated with the second camera brand are not quite as encouraging. A little over $17 \%$ of the variance in the criterion variable is accounted for, and only two predictors-cognitive differentiation and number of purchases-are significant at the 0.05 level. In both camera data sets, all eight predictor-criterion correlation coefficients achieve significance $(p<0.05)$. Thus, there is strong evidence to support Hypotheses 4 and 5 (which concern cognitive differentiation and number of purchases). However, there is weak support for Hypotheses 2 and 3, as the beta weights associated with interest and experience achieve significance $(p<0.05)$ in only one of the two camera data sets.

Table 5 presents the results associated with the ice cream brands. Again, all coefficients are signed in the hypothesized direction, and a substantial portion of the variance in the criterion variables is accounted for-over $31 \%$ for the first ice cream brand and over $34 \%$ for the second ice cream brand. The beta weights for number of purchases are significant $(p<0.01)$ for both ice cream brands. The same is true of the interest beta weights. However, the beta coefficient for cognitive differentiation achieves significance $(p<0.05)$ only for the second ice cream brand. Product experience is never a significant predictor in the regression setting. Again, all eight predictor-criterion correlation coefficients are significant $(p<0.05)$.

The four predictor variables-experience, number of purchases, product interest, and cognitive structure-are conceptually similar; and there was a possibility that multicollinearity could be a problem in this data set. The main problem associated with multicollinearity is that a predictor variable may not share enough unique variance with the criterion variable in order to assess the true effect of the predictor variable on the criterion variable. In this particular case, however, the conceptual association between the predictor variables did not appear to be a 
problem. With the exception of product experience, all the predictor variables have sufficient unique variation to appear significantly associated with Att $_{\mathrm{Name}}$. An examination of $R_{i}^{2}$ values revealed that this failure to achieve significance was not due to potentially troublesome linear associations with the other predictor variables. $R_{i}^{2}$ is the squared multiple correlation of predictor variable $i$ with the other predictor variables and serves as a measure of multicollinearity [19]. In this study, the values of $R_{i}^{2}$ ranged from 0.09 to 0.21 with a mean value of 0.16 . Thus, multicollinearity does not appear to be a problem in this data set.

In summary, as revealed by the beta weights, strong support is found for $\mathrm{Hy}$ potheses 3 through 5 , which relate to product interest, cognitive differentiation, and number of purchases, respectively. In the case of product interest and cognitive differentiation, three out of four beta weights proved to be significant $(p<0.05)$. All four of the beta weights for number of purchases are significant $(p<0.01)$. There was weak support for Hypothesis 2, as only one of the four experience beta weights is sizable enough to achieve significance at the 0.05 level.

\section{Cross-Validation Results}

The regression equations represented in Tables 4 and 5 were used to predict brand name attitudes for the 82 respondents in the validation sample. The correlations between predicted and actual values are 0.347 and 0.366 for the two camera brands; both correlations are significant $(p<0.01)$. The correlations between predicted and actual values for the two ice cream brands are 0.374 and 0.515 . Both of these correlation coefficients are significant at the 0.001 level. Note that there is quite a bit of shrinkage in the explained variance when moving from the estimation sample to the validation sample. This shrinkage is most severe in the case of one of the camera brands where explained variance falls from $31 \%$ to $12 \%$. The most successful prediction results are found for one of the ice cream brands where explained variance drops from $35 \%$ to $27 \%$.

As a further test of the proposed model, these prediction results were compared with those of a naive model that used unit weights for each of the predictors. In no instance does the naive model outperform the estimated model. However, the naive model is fairly successful, with correlations between predicted and actual values being 0.251 and 0.300 for the camera brands and 0.322 and 0.364 for the ice cream brands. Thus, the beta weights shown in Tables 4 and 5 are not very precise. Nonetheless, both the estimated model and the naive model provide evidence to suggest that the predictors are positively related to brand name attitude formation, and both models provide further evidence to support Hypotheses 2 through 5 .

\section{Discussion}

We found that attitudes toward typical names benefit from a process of inferential belief formation, whereas atypical names do not. That is, typically named brands are perceived more favorably than atypically named brands. Four individual difference variables - experience, number of purchases, cognitive differentiation, and product interest-partially explain these favorable attitude shifts.

The data give credence to our contention that brand name attitudes exist in- 
dependent of product attitudes. Brand names which are premeasured as being more "remindful" of their respective product categories generated more positive beliefs than those which were less remindful. The brand name's evocation of "fitting" associations adds to the likelihood that positive beliefs will accrue to the subsequent product's perception. In one sense, Att $_{\text {Name }}$ is not separable from $\mathrm{Att}_{\mathrm{Brand}}$ since, by definition, the reaction to the brand name would be quite different if attached to a different product category [28]. But in another sense, Att $_{\text {Name }}$ and $\mathrm{Att}_{\mathrm{Brand}}$ are separable since it is possible to distinguish between them using an attitude measurement scale.

\section{Implications of Findings for Management}

These results have implications for the marketing manager involved in naming new brands. Peterson and Ross [26] suggest that a "typical" brand name would be best. If a new brand is given a name that is congruent with names of existing brands in a relevant product class, then consumers will tend to assume a "fit" of the new brand in that product class. The supposition is that the new brand becomes a more acceptable entrant and capitalizes upon existing positive attitudinal associations. In terms of the Howard-Sheth [16] schema, the new brand would now be positioned further along the learning curve because of the brand name itself. Another strategic implication is that an "atypical" name produces negative, or at best neutral, attitudes toward the new brand. Although this may mean starting from a less-favorable position for the brand - forcing a greater task on the advertising for the new brandit may have a long-run positive aspect. The idea here is that the new brand will be divorced from attitudes associated with existing, and competing, brands within the product category. This means the new brand will have the potential for truly independent consumer attitudes. From a marketing standpoint, the new brand can establish a more unique position within the product class. The implication we see in this choosing between a typical and an atypical name for a new brand is the long-run strategic position desired for the brand. If the new brand has truly new and unique attributes, then perhaps an atypical name may prove superior. However, if the new entrant is a "me-too" product, then a typical name may be best. Certainly this strategy tradeoff is a ripe area for future research.

Over time, an advertiser may be able to imbue a brand name with certain imagery. But, the results reported here suggest that some brand names may be more promotable than others in the sense that they are more remindful of the product category. These remindful brands may start off with an advantage in the marketplace, and typically named brands may be more successful in the long run as Bogart and Lehman [4] suggest.

These results have implications for the field of copy testing. When researching advertisements for new brands, it may be best to assess consumer attitudes both before and after exposure to the advertisements themselves. In this way it may be possible to separate out reactions to the brand name from reactions to the advertisements.

Another important consideration for advertising researchers is the possible interaction effect between ad copy and brand name. That is, some ad copy may work very well with one brand name and yet be inappropriate for a second name. 
Advertisers have to be careful to match their promotional strategy with the image evoked by the brand's name.

It may be that favorable reactions to the brand name may not necessarily translate into increased purchase probability, especially if an inferential belief is contradicted by point-of-purchase inspection. The experimental condition tested here is very artificial in that brand name was the only cue present. Thus, when selecting a name it is important to consider other factors (e.g., packaging, word-of-mouth, price, etc.) that will affect inferential belief formation.

\section{Limitations of Study}

There are some limitations associated with the present investigation. First, the model tested here assumes high involvement information processing. Second, this investigation was cross-sectional, and consumers' reactions to new brand names were studied at only one time. It may be interesting to track brand name attitudes across time. A third limitation was the brand names selected for study. Even though the results from two surveys (one group of experts and one group of consumers) support our classification scheme, it is rather difficult to precisely identify one brand name as typical and one as atypical.

Finally, measurement of the predictor variables could be improved. For example, when "number of prior purchases" is used as an "experience" measure, it fails to capture the quality of the purchase (e.g., purchase of a lens vs. purchase of an inexpensive disk camera). Thus, in future investigations, it may be productive to ask subjects to describe their prior purchases in some detail rather than merely asking for a frequency count.

\section{Summary}

In this investigation we identified four predictors of Att $_{\text {Name }}$. These predictors were successful both in the original sample and in the cross-validation sample. As revealed by the size of the beta coefficients, number of trials is the most important predictor variable. This finding is consistent with some of the corollaries of the Howard-Sheth [16] model concerning extensive problem solving and limited problem solving. In summary, as a person experiences more trials within a product class, he forms stronger and stronger attitudes toward some brand within that classification. Thus, a "typically" named brand will benefit from a transference of positive attitudes.

The naming of a product is a complex and difficult task. Others have pointed out that a ncw product name should be short, easy to pronounce, potentially memorable, and should maximize product positioning. In brief, a new product name should be able to communicate messages important to consumers. In addition to this, as our findings indicate, the naming of a product can have immediate attitudinal implications. Based on a product name alone, customers form instant, nonneutral attitudes about the product that may prove difficult to change through the use of subsequent communications. 
The authors thank William B. Locander of the University of Tennessee for his comments on an earlier draft of this paper. Furthermore, George Zinkhan gratefully acknowledges the support of the College of Business Administration's Summer Faculty Research Program at the University of Houston.

\section{References}

1. Ash, Stephen A. Consumer Satisfaction, Dissatisfaction, and Complaining Behavior: Major Findings and Directions for Action, in (S. A. Ash, ed.), Summary of Report Submitted to Consumer and Corporate Affairs of Canada. Toronto: Consumer and Corporate Affairs of Canada, December, 1979.

2. Bagozzi, R. P. An Examination of the Validity of Two Models of Attitude, Cambridge, Mass.: Working Paper, Sloan School of Management, MIT (1981).

3. Bieri, James, Atkins, Alvin L., Briar, Scott, Lehman, R. L., Miller, Henry, and Tripodi, Tony. Clinical and Social Judgement: The Discrimination of Behavioral Information. New York: Wiley, (1966).

4. Bogart, Leo and Lehman, Charles. What Makes a Brand Name Familiar? Journal of Marketing 10: 17-22 (February 1973).

5. Buchanan, Dodds I. How Interest in the Product Affects Recall: Print Ads vs. Commercials. Journal of Advertising Research 4: 9-14 (1964).

6. Davis, Kenneth R. Marketing Management, 4th edition. New York: Wiley (1981), pp. 325.

7. Diener, Betty J. and Greyser, Stephen A. Consumer Views of Redress Needs. Journal of Marketing 42: 21-27 (1978).

8. Doyle, Willard H. Brand Still Critical. Marketing News: 12:38 (1978).

9. Durand, Richard M. Cognitive Complexity, Attitudinal Affect, and Dispersion in Affect Ratings for Products. Social Psychology 107: 209-12 (1970).

10. Elling, K. A. Introduction to Modern Marketing: An Applied Approach. New York: The MacMillan Company (1970).

11. Feakins, Kathryn. What's in a Name? Ogilvy \& Mather Research: The Research File No. 17 (March 1980).

12. Fishbein, Martin and Ajzen, J. Belief Attitude, Intention, and Behavior. Reading, Mass.: Addison-Wesley (1975).

13. Fornell, Claes. Consumer Input for Marketing Decisions: A Study of Corporate Departments for Consumer Affairs. New York: Praeger (1976).

14. Gardner, Burleigh and Levy, Sidney .I. The Product and the Brand. Harvard Bus Rev 33: 36 (March-April 1955).

15. Goodwin, Stephen and Etgar, Michael. An Experimental Investigation of Comparative Advertising: Impact of Message Appeal, Information Load, and Utility of Product Class. Journal of Marketing Research 17: 187-202 (May 1980).

16. Howard, John A. and Sheth Jagdish N. The Theory of Buyer Behavior. New York: Wiley (1969), Chapters 2 and 3.

17. Huber, Joel and McCann, John. The Impact of Inferential Beliefs on Product Evaluations. Journal of Marketing Research 19: 324-33 (August, 1982).

18. Juster, F. Thomas. Anticipations and Purchases: An Analysis of Consumer Behavior. Princeton, N.J.: National Bureau of Economic Research (1964).

19. Kenny, David A. Correlation and Causality. New York: Wiley (1979).

20. Leone, Robert P. The Effect of an Individual's Sex on Preference for Brand Names, 
in Bernhardt, et al., eds., The Changing Marketing Environment: New Theories and Applications. Chicago: American Marketing Association. (1981), pp. 197-200.

21. Lutz, Kathy A. and Lutz, Richard J. Effects of Interactive Imagery on Learning: Application to Advertising. Journal of Applied Psychology 62: 493-98 (No. 4 1977).

22. Marascuilo, Leonard A. and Levin, Joel R. Multivariate Statistics in the Social Sciences. Monterey, Calif.: Brooks/Cole (1983).

23. Mitchell, Andrew and Olson, Jerry. Are Product Attitude Beliefs the Only Mediator of Advertising Effects on Brand Attitude? Journal of Marketing Research 18: 318-32 (August 1981).

24. Olson, Jerry C. Inferential Belief Formation in the Cue Utilization Process in H. Keith Hunt, ed., Advances in Consumer Research, vol. 5. Ann Arbor: Mich. Association for Consumer Research (1981), pp. 706-13.

25. Olson, Jerry C. Encoding Processes: Levels of Processing and Existing Knowledge Structures, in Jerry C. Olson, ed., Advances in Consumer Research, vol. 7. Ann Arbor, Mich. Association for Consumer Research (1980), pp. 154-60.

26. Peterson, Robert A. and Ross, Ivan. How to Name New Brands. Journal of Advertising Research 12: 29-34 (December 1972).

27. Rigaux-Bricmont, B. Influences of Brand Name and Packaging on Perceived Quality, in A. Mitchell, ed., Advances in Consumer Research, vol. 9. Ann Arbor, Mich. Association for Consumer Research (1982), pp. 472-77.

28. Ross, Ivan. Personal Communication, 1982.

29. Ryan, Michael J. and Bonfield, E. H. The Fishbein Extended Model and Consumer Behavior. Journal of Consumer Research 21: 118-36 1975.

30. Scott, William A. Cognitive Complexity and Cognitive Flexibility. Sociometry 25: 405141962.

31. Westbrook, Robert A., Newman, Joseph W., and Taylor, James R. Satisfaction/ Dissatisfaction in the Purchase Decision Process. Journal of Marketing 42: 54-69 (1978).

32. Wyler, Robert S. Cognitive Organization and Change: An Information Processing Approach. Hillside, N.J.: Lawrence Erlbaum (1974).

33. Zinkhan, George $M$. and Martin, Claude R. The Attitudinal Implications of a New Brand's Name, in A. Mitchell, ed., Advances in Consumer Research, vol. 9, Ann Arbor, Mich.: Association for Consumer Research (1982), pp. 467-71. 